

REVISTA ELETRÔNICA EM CIÊNCIAS DA RELIGIÃO - UNICAP

Dossiê

ISSN2178-8162

GATOLICA

Lideranças, testemunhos e profetismo religioso na América Latina

doi: 10.20426/P.2178-8162.2016v7n16p501

\title{
PRÁTICAS DE BEM MORRER E O USO DA MORTALHA EM SERGIPE - NORDESTE- BRASIL - SÉCULOS XVIII E XIX
}

\author{
Hortência de Abreu Gonçalves \\ Kathia Cilene Santos Nascimento ${ }^{* \star}$ \\ Lilian de Lins Wanderley ${ }^{\star \star \star}$ \\ Marilene Batista da Cruz Nascimento ${ }^{* * * *}$
}

\section{RESUMO}

Escolher a roupa do próprio sepultamento sempre suscitou expectativas. O medo da morte e do que viria depois fez com que homens e mulheres se preocupassem em preparar, antecipadamente, a roupa da passagem da vida material para a espiritual. No imaginário coletivo religioso cristão predominava a ideia de que o uso da mortalha facilitaria a entrada da alma no Reino de Deus. Objetivou-se verificar a escolha da mortalha em Sergipe, no período de 1780-1850, em 155 testamentos "postem mortem", do Arquivo Judiciário do Estado de Sergipe (AJES). Pesquisa bibliográfica e documental, pautada na História das Mentalidades e no método de análise de conteúdo. A solicitação da mortalha fez-se presente na documentação, variando desde roupa de santos preferenciais e invocações de Nossa Senhora, até indumentárias de anjo, vestes papais e mortalhas brancas e pretas.

Palavras-chave: Mortalha. Mentalidade. Sergipe. Bem morrer.

Pós-doutora em Estudos Culturais pelo Programa Avançado de Cultura Contemporânea (PACC)/Fórum de Ciência e Cultura (FCC) - Universidade Federal do Rio de Janeiro. Doutora em Geografia pela Universidade Federal de Sergipe. Professora da Universidade Tiradentes -UNIT e das Faculdades Estácio e FANESE de Sergipe. E-mail: ensino.pesquisa@yahoo.com.br.

** Mestranda em Educação pela Universidade Tiradentes. Professora da Universidade Tiradentes UNIT, Sergipe. E-mail: kathia.pesquisa@outlook.com.

*** Doutora em Geografia pela Universidade Estadual Paulista Júlio de Mesquita Filho - UNESP, Rio Claro. Professora associada da Universidade Federal de Sergipe, nos cursos de doutorado, mestrado e graduação, em Geografia. E-mail: lilianwanderley@uol.com.br.

**** Doutora em Educação pela Pontifícia Universidade Católica do Rio Grande do Sul - PUCRS. Mestra em Educação pela Universidade Tiradentes - Unit. Professora adjunta da Universidade Federal de Sergipe (UFS). E-mail: nascimentolene@yahoo.com.br. 


\section{INTRODUÇÃO}

No cotidiano brasileiro, além da religiosidade praticada pelo cristão de forma individual, recomendava-se a "toda gente participar das cerimônias, umas dentro, outras fora dos templos, tais como as celebrações da Semana Santa, as frequentes procissões, bênçãos do Santíssimo, trezenas, novenas, tríduos [...] de sua freguesia, as romarias e santas missões" (MOTT apud SOUZA, 1997, p.160), tradições trazidas de Portugal, desde o descobrimento.

Ao que parece, tanto no campo quanto na zona urbana, "a cidade religiosa do fiel estava centrada em relações diretas, pessoais com os santos" (MATTOSO, 1992, p.392). A religiosidade do povo era encorajada pela família e por toda a sociedade. Algumas famílias possuíam o quarto dos santos ou aposentos com várias imagens e oratório que funcionava como relicários de devoção aos santos preferenciais.

As orações eram praticadas diariamente e objetivavam a cura de doenças, malefícios, preservação da riqueza material e a superação de infortúnios ou desventuras que por acaso o fiel tivesse ou viesse sofrendo. Preocupações com o bem morrer se fizeram presente, de modo que várias pessoas procuraram amenizar os pecados cometidos ao longo da vida, tanto por meio da prestação de contas via sacramento da confissão, quanto pela feitura do testamento, concedendo benefícios e doando bens em prol da salvação da sua alma. O testamento, documento redigido pelo Tabelião de Notas e registrado em cartório, formalizava os últimos desejos do testador, entre estes o local de sepultamento, o hábito mortuário, o rito fúnebre e compromissos com a reserva de virtudes e até doações de bens materiais para terceiros, atitudes que promoveriam a entrada da alma no paraíso.

A tríade Céu, Purgatório e Inferno povoava o imaginário religioso, sendo o Purgatório a antessala do Inferno e local em que a alma passaria pela pesagem dos pecados cometidos na vida material. Nesse contexto, religiosos incentivavam a leitura de manuais como Methodo D'ajudar o Bem Morrer (1811) (REIS, 1991, p.106).

Em Sergipe, testadores também se preocuparam com os preceitos do catolicismo repassados aos fiéis, fazendo com que homens e mulheres, antes de morrer, instituíssem doações, heranças, promessas a Santos, ex-votos e esmolas aos pobres, 
escravos e ex-escravos, Irmandades, Confrarias, Ordens Religiosas e Cartas de Alforria a escravos preferenciais. Firmar alianças com Deus e seus intercessores celestiais, facilitaria a passagem do lado dos vivos para o lado dos mortos, associado a necessidade de alguns ajustes para evitar o fogo do Inferno, fazendo com que lembrassem de parentes mortos, desafetos e atrocidades cometidas contra cativos e terceiros. Nessa ocasião, "forravam seus escravos 'por amor' e perdoavam dívidas, sabendo que a caridade era imprescindível à salvação" (DEL PRIORI apud SOUZA, 1997, p. 324).

A presença do Juízo Final no imaginário do colono e o medo do Inferno, de onde não se podia sair, aterrorizavam o moribundo e o "momento de preparar-se para morrer permitia um retrospecto da vida em que se desenrolavam as relações sociais e familiares que a tinha marcado" (DEL PRIORI apud SOUZA, 1997, p.319), evidenciando o seu papel no âmbito social. Ao testamenteiro cabia a execução do testamento no prazo determinado pelo testador.

A pesquisa objetivou verificar a escolha da mortalha em Sergipe, no período de 17801850, em 155 testamentos "postem mortem", do Arquivo Judiciário do Estado de Sergipe (AJES). Pesquisa bibliográfica e documental, pautada na História das Mentalidades e no método de análise de conteúdo, contemplando 140 testamentos "post mortem" e 35 inventários, 15 deles contendo testamentos, totalizando 190 documentos dos séculos XVIII e XIX, sendo 97 para o sexo masculino e 78 para o feminino, oriundos da Capitania de Sergipe d'El Rey e posterior Província de Sergipe, localizada na Região Nordeste do Brasil. Documentos manuscritos pertencentes ao Arquivo Judiciário do Estado de Sergipe que foram levantados por Hortência de Abreu Gonçalves, por ocasião da pesquisa que serviu de base à sua dissertação de Mestrado em Sociologia da Universidade Federal de Sergipe, intitulada "As Cartas de Alforria e a Religiosidade: Sergipe (1780-1850)." O acervo de informações por ela construído na sua pesquisa é agora revisado com a colaboração dos coautores do presente artigo.

A coleta de novos dados e os estudos procedentes, com foco no período 1780 a 1850 , contemplaram a mesma região focalizada na dissertação da autora, a chamada Zona da Cotinguiba, de características geográficas que a vocacionavam para a produção de açúcar nos antigos engenhos, desenvolvida nas grandes propriedades rurais e 
sustentada pela mão-de-obra escrava de origem africana. Nesta região se identificam os atuais municípios Capela, Siriri, Riachuelo, Divina Pastora, Rosário do Catete, Laranjeiras, Maruim, Nossa Senhora do Socorro e Santo Amaro das Brotas, e fora dessa Zona, o município de Itabaiana. A História das Mentalidade associada ao método de análise de conteúdo, forneceu as diretrizes teórico-metodológicas das análises efetuadas neste estudo.

\section{PRÁTICAS DE BEM MORRER E O USO DA MORTALHA EM SERGIPE}

Por ocasião da morte as emoções tornavam-se extremamente complexas, confusas e contraditórias e o rito fúnebre tinha início com a chegada de parentes e amigos para a contemplação do defunto. Imediatamente, todos recorriam ao sinal da cruz, associado ao padre-nosso, ave-maria e credo, rezados por diversas vezes no entorno do corpo inerte. Rosários, ladainhas e benditos também eram desfiados, recitados e cantados em referência ao morto e celebrações litúrgicas, muitas delas em sua presença, visavam a que a alma alcançasse a paz eterna. Já o sepultamento, em sua maioria, era feito em capelas e igrejas, muitas vezes construídas durante a vida material do morto.

Também se recorria à Extrema Unção, considerado

o mais importante momento de todo o ritual e, caso o doente estivesse à beira da morte, o sacerdote tinha que apressar 0 cerimonial, para que houvesse tempo de o indivíduo ser untado com os santos óleos. Rapidamente, o moribundo tinha seus olhos, orelha, nariz, boca e mãos ungidos. Necessário se fazia eliminar os sinais do mal e, assim, preparar os sentidos, já que, segundo a crença cristã, seria através deles que adquirimos o pecado. Posteriormente, e se existisse tempo, outras partes do corpo também recebiam a unção, evitando-se os seios e as costas, se o moribundo fosse uma mulher (RIBEIRO, [s.d.], p.3).

A última confissão do moribundo na presença do padre incluía o pedido de perdão dos pecados cometidos, a eucaristia significava que aquele que se despedia da vida entrava em comunhão com o corpo de Cristo ressuscitado, e assegurava que logo estaria ao lado de Deus. Em testamento datado de 04 de março de 1816, é possível visualizar esse ritual, conforme segue: 
Corpo conduzido para a dita matriz em um caixão honesto, sem pompa alguma e sepultado junto da Capela do Senhor Bom Jesus da Boa Morte, donde se mandará dizer um ofício rezado, pelo meu reverendo vigário e oito sacerdotes, mais que façam nove e a cada um deles dirão uma missa de corpo presente e depois de recolhido na sepultura os ditos senhores sacerdotes, rezarão cada um, um responsório ${ }^{1}$ pela minha alma e a encomendação só quero seja a de obrigação e essa rezada por todos os 09 padres sem solenidade alguma, e me mandarão dizer cinco oitavários ${ }^{2}$ de missas também por minha alma" usando hábito de Nossa Senhora do Carmo. ${ }^{3}$

Doações vultosas em vida para a Igreja, inclusive de bens de raiz, como engenhos, sítios e fazendas eram realizadas em troca do sepultamento em suas dependências ou em capelas contíguas, como a que está datada de 11 de agosto de $1756^{4}$, onde se observa uma doação entre vivos, feita por um Coronel e sua mulher ao Pe. Provincial e mais religiosos do Convento de Nossa Senhora do Carmo - Carmelitas Calçados da Província da Bahia. A doação importou em uma Igreja e uma capela localizada no sítio Comandaroba, com casas de vivenda engenho de açúcar, além de terras e mais dois mil cruzados. Em troca, ficava a obrigação perpétua de uma missa todos os sábados com incenso, exceto Sábado de Aleluia, Natal e Dia de Finados, tendo como intenção a alma dos doadores.

O uso do hábito mortuário, conhecido como mortalha, "sugere um apelo à proteção dos Santos nelas invocados e sublinha a importância do cuidado com o cadáver na passagem para o além [...]" (REIS apud ALENCASTRO, 1998, p.114). Vestir-se de Santo facilitava a entrada na corte divina e para tanto havia especialistas para essa conduta, pessoa honesta e devota que guardava simpatia com o defunto. Orações faziam parte desse ritual:
Veste essa mortalha, ${ }^{5}$
Quem mandô foi Deus;
Quem mandô vesti;
Foi a Mãe de Deus.

\footnotetext{
1 Parte da liturgia dos defuntos que compreende o canto dos Salmos e a Sequência dos fiéis defuntos.

2 Lote de oito missas celebradas sequencialmente, desde o falecimento até o oitavo dia do sepultamento.

${ }^{3}$ Testamento "post mortem" datado de 04.03.1816, CSC $1^{\circ}$ Ofício Cx02 - Arquivo Judiciário do Estado de Sergipe (AJES).

${ }^{4}$ Arquivo Ultramarino - Cx 06 - n50 - CEMIC/UFS.

${ }^{5}$ Bendito de vestir defunto com hábito de São Francisco, recolhido em Pernambuco por Getúlio César (ALENCASTRO, 1998).
} 


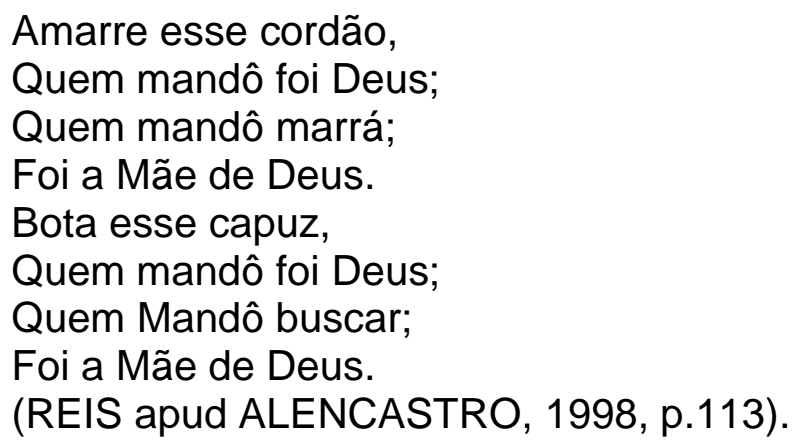

A oração continuava sendo repetida a cada peça vestida "sete deviam ser os nós do cordão da mortalha, sendo rezado um Pai - Nosso e uma Ave - Maria para cada nó, portanto, um total de catorze [sic!] preces, além do Bendito" (REIS apud ALENCASTRO, 1998, p.114). Também foram criadas orações especiais encaminhadas as almas, aos Santos e ao Anjo da Guarda:
Anjo da Guarda
Bem Aventurado
Convosco meu Anjo
Tenho-me pagado.
Quando eu for chamado
De Aquele Senhor
Ajudai-me meu Anjo
No Céu a subir.
Meu Anjo da Guarda
Meu Jesus também
Me levai à glória
Para sempre. Amém!
(SILVIO ROMERO apud REIS, 1991, p. 223).

Os testamentos estudados revelam a predominância de hábitos mortuários nas cores brancas e preta e ainda, nas várias invocações de Nossa Senhora, São Pedro, São José e em especial, São Francisco de Assis, herança ibérica da Idade Média, quando em Portugal, as pessoas pediam "que seus cadáveres fossem amortalhados com hábito de São Francisco" (REIS, 1991, p.117). No Quadro 1 são mostradas as determinações de testadores quanto ao local de sepultamento e hábito mortuário.

Quadro 1 - Local de sepultamento e hábito mortuário. Sergipe (1780 - 1850).

\begin{tabular}{|l|l|l|l|l|}
\hline \multicolumn{1}{|c|}{$\begin{array}{c}\text { Local de } \\
\text { Sepultamento }\end{array}$} & \multicolumn{2}{c|}{74 MULHERES } \\
\hline Igreja/Capela & Quantidade & Tipo de Hábito & Quantidade & Tipo de Hábito \\
\hline
\end{tabular}




\begin{tabular}{|c|c|c|c|c|}
\hline $\begin{array}{ll}\text { Matriz } & \text { de } \\
\text { Nossa } & \\
\text { Senhora } & \text { do } \\
\text { Socorro da } & \text { dotinguiba } \\
\end{array}$ & $\begin{array}{l}1 \\
3 \\
2\end{array}$ & $\begin{array}{l}\text { Branco } \\
\text { São Francisco } \\
\text { Nossa Senhora do Carmo }\end{array}$ & 6 & São Francisco \\
\hline $\begin{array}{lr}\text { Matriz da } & \text { Vila } \\
\text { de } & \text { Santo } \\
\text { Amaro } & \text { das } \\
\text { Brotas } & \end{array}$ & $\begin{array}{l}2 \\
1\end{array}$ & $\begin{array}{l}\text { São Francisco } \\
\text { Branco }\end{array}$ & $\begin{array}{l}1 \\
1 \\
1\end{array}$ & $\begin{array}{l}\text { Nossa Senhora do Carmo } \\
\text { São Francisco } \\
\text { Branco }\end{array}$ \\
\hline $\begin{array}{l}\text { Igreja de } \\
\text { Senhora } \\
\text { Santana de } \\
\text { Santo Amaro }\end{array}$ & & & 1 & Branco \\
\hline $\begin{array}{l}\text { Matriz de } \\
\text { Nossa senhora } \\
\text { do Rosário do } \\
\text { Sacco do } \\
\text { Catete }\end{array}$ & 1 & Sem Identificação & 1 & Nossa Senhora do Carmo \\
\hline $\begin{array}{l}\text { Matriz da } \\
\text { Ordem } \\
\text { Terceira de } \\
\text { São } \\
\text { em Francisco } \\
\text { Cristóvão }\end{array}$ & $\begin{array}{l}1 \\
2\end{array}$ & $\begin{array}{l}\text { Branco } \\
\text { São Francisco }\end{array}$ & $\begin{array}{l}2 \\
1\end{array}$ & $\begin{array}{l}\text { São Francisco } \\
\text { Branco }\end{array}$ \\
\hline $\begin{array}{l}\text { Matriz de } \\
\text { Santa Luzia }\end{array}$ & 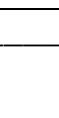 & 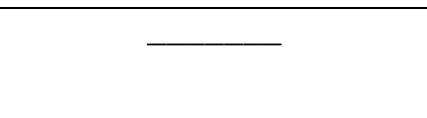 & $\begin{array}{l}2 \\
1\end{array}$ & $\begin{array}{l}\text { Nossa Senhora do Carmo } \\
\text { São Francisco }\end{array}$ \\
\hline $\begin{array}{ll}\text { Matriz de } \\
\text { Nossa } \\
\text { Senhora da } \\
\text { Guadalupe de } \\
\text { Estância }\end{array}$ & $\begin{array}{l}3 \\
2\end{array}$ & $\begin{array}{l}\text { São Francisco } \\
\text { Branco }\end{array}$ & $\begin{array}{l}1 \\
1 \\
1\end{array}$ & $\begin{array}{l}\text { Preto } \\
\text { Branco } \\
\text { São Francisco }\end{array}$ \\
\hline $\begin{array}{l}\text { Matriz de } \\
\text { Divina Pastora }\end{array}$ & 3 & São Francisco & $\begin{array}{l}1 \\
1\end{array}$ & $\begin{array}{l}\text { Nossa Senhora do Carmo } \\
\text { São Francisco }\end{array}$ \\
\hline $\begin{array}{ll}\text { Matriz } & \text { de } \\
\text { Nossa } & \\
\text { Senhora } & \text { da } \\
\text { Piedade } & \text { do } \\
\text { Lagarto } & \end{array}$ & $\begin{array}{l}2 \\
2\end{array}$ & $\begin{array}{l}\text { São Francisco } \\
\text { Não menciona }\end{array}$ & $\begin{array}{l}2 \\
2\end{array}$ & $\begin{array}{l}\text { Qualquer hábito } \\
\text { Não menciona }\end{array}$ \\
\hline
\end{tabular}

Paralellus, Recife, v. 7, n. 16, set./dez. 2016, p. 501-514 


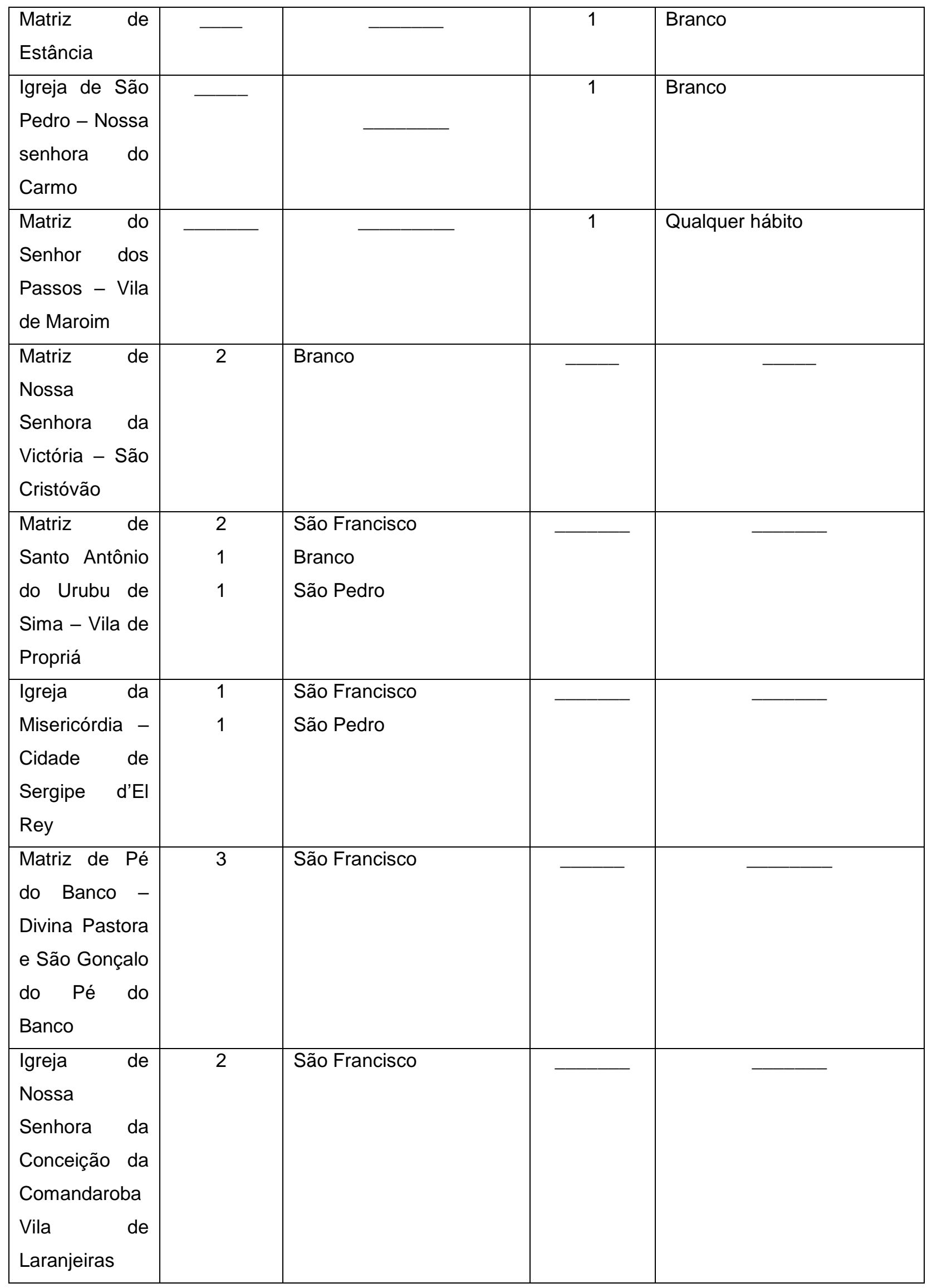




\begin{tabular}{|c|c|c|c|c|}
\hline $\begin{array}{l}\text { Matriz de } \\
\text { Laranjeiras }\end{array}$ & 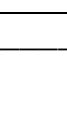 &  & 1 & Preto simples \\
\hline $\begin{array}{l}\text { Igreja de } \\
\text { Nossa senhora } \\
\text { do Rosário - } \\
\text { Vila de Santo } \\
\text { Amaro das } \\
\text { Brotas }\end{array}$ & $\begin{array}{l}2 \\
1\end{array}$ & $\begin{array}{l}\text { Brancos } \\
\text { Preto }\end{array}$ & 1 & Nossa Senhora do Carmo \\
\hline $\begin{array}{l}\text { Capela de } \\
\text { Nossa } \\
\text { Senhora do } \\
\text { Rosário da Vila } \\
\text { Nova }\end{array}$ & $\begin{array}{l}1 \\
1 \\
1\end{array}$ & $\begin{array}{l}\text { Branco } \\
\text { São Francisco } \\
\text { Nossa Senhora do Carmo }\end{array}$ & 1 & São Francisco \\
\hline \begin{tabular}{lr} 
Capela & do \\
Senhor & Bom \\
Jesus & de \\
Santo & Amaro \\
\multicolumn{2}{l}{ das Brotas }
\end{tabular} & 3 & São Francisco & 1 & São Francisco \\
\hline $\begin{array}{l}\text { Capela de } \\
\text { Nossa } \\
\text { Senhora da } \\
\text { Purificação - } \\
\text { Pé do } \\
\text { Banco/Divina } \\
\text { Pastora- }\end{array}$ & 1 & $\begin{array}{l}\text { Hábito de Sacerdote na } \\
\text { forma Romana }\end{array}$ & & \\
\hline $\begin{array}{l}\text { Capela de } \\
\text { Nossa } \\
\text { Senhora do } \\
\text { Amparo - Vila } \\
\text { de Estância }\end{array}$ & 1 & Branco & & 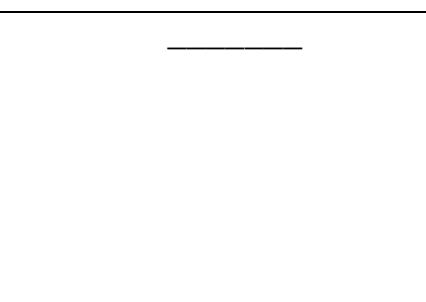 \\
\hline $\begin{array}{l}\text { Capela do } \\
\text { Santíssimo } \\
\text { Coração de } \\
\text { Jesus - Vila de } \\
\text { Laranjeiras }\end{array}$ & $\begin{array}{l}1 \\
1\end{array}$ & $\begin{array}{l}\text { São Francisco } \\
\text { Nossa Senhora do Carmo }\end{array}$ & & \\
\hline $\begin{array}{l}\text { Capela de } \\
\text { Santo Antônio }\end{array}$ & 1 & Branco & & 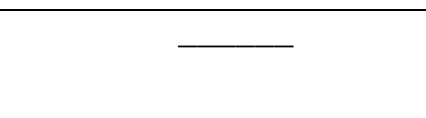 \\
\hline
\end{tabular}

Paralellus, Recife, v. 7, n. 16, set./dez. 2016, p. 501-514 


\begin{tabular}{|c|c|c|c|c|}
\hline $\begin{array}{l}\text { da Barra de } \\
\text { Propriá }\end{array}$ & & & & \\
\hline $\begin{array}{lr}\text { Capela de } \\
\text { Nossa } \\
\text { Senhora de } \\
\text { Nazaret } & \text { - Vila } \\
\text { de } \quad \text { Santo } \\
\text { amaro das } \\
\text { Brotas }\end{array}$ & 1 & São Francisco &  & \\
\hline $\begin{array}{l}\text { Capela de } \\
\text { Nossa } \\
\text { Senhora } \\
\text { Santana do } \\
\text { Masacará - } \\
\text { Vila Nova do } \\
\text { Rio de São } \\
\text { Francisco }\end{array}$ & 1 & Nossa Senhora do Carmo & & \\
\hline $\begin{array}{lr}\text { Capela da } \\
\text { Irmandade de } \\
\text { Nossa } \\
\text { Senhora do } \\
\text { Rosário - Vila } \\
\text { de Santo } \\
\text { Amaro das } \\
\text { Brotas }\end{array}$ & 2 & São Francisco & & \\
\hline $\begin{array}{l}\text { Cemitério de } \\
\text { Estância }\end{array}$ & $\begin{array}{l}1 \\
1\end{array}$ & $\begin{array}{l}\text { Qualquer lençol branco } \\
\text { Escolhido pelo } \\
\text { testamenteiro }\end{array}$ & 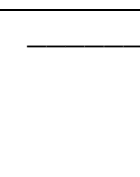 & \\
\hline $\begin{array}{l}\text { Carneiro do } \\
\text { Convento de } \\
\text { São Francisco } \\
\text { - Vila de São } \\
\text { Cristóvão }\end{array}$ & 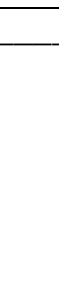 &  & 1 & São Francisco \\
\hline $\begin{array}{l}\text { Capela de } \\
\text { Nossa senhora } \\
\text { da Guia do } \\
\text { Engenho } \\
\text { Gameleira }\end{array}$ & & & 1 & São Francisco \\
\hline
\end{tabular}




\begin{tabular}{|c|c|c|c|c|}
\hline $\begin{array}{l}\text { Convento da } \\
\text { Ordem de } \\
\text { Nossa } \\
\text { Senhora do } \\
\text { Carmo - São } \\
\text { Cristóvão }\end{array}$ &  &  & 1 & Não Menciona \\
\hline $\begin{array}{l}\text { Capela do } \\
\text { Santíssimo } \\
\text { Sacramento - } \\
\text { sem } \\
\text { localização }\end{array}$ & 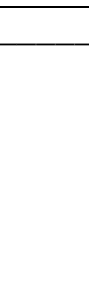 & 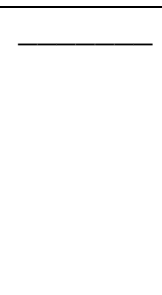 & 1 & Preto \\
\hline $\begin{array}{l}\text { Não } \\
\text { Identificados }\end{array}$ & 24 & & 37 & \\
\hline
\end{tabular}

Fonte: 155 Testamentos "post mortem" de Sergipe entre os anos de 1780-1850. Arquivo Judiciário do Estado de Sergipe (AJES).

A predominância da mortalha de São Francisco (47 solicitações) teve como motivação o imaginário de que a alma, antes de ter o seu destinatário definido, precisava passar pelo purgatório para a verificação de seus pecados no fiel da balança e, se por acaso o Diabo tripudiasse e a alma escorregasse para o fundo do Inferno, os anjos podem salvá-la, puxando pelo cordão de São Francisco (REIS, 1991).

No imaginário popular religioso, a roupa fúnebre podia facilitar a entrada no ambiente celestial, tendo como protetor, o(a) santo(a) em sua representação simbólica. Acreditava-se ser possível entrar no mundo dos mortos, feliz e plenamente. Associado a isso, o sepultamento representava a condição socioeconômica do morto e "[...] na ausência do caixão, [recorria-se ao] uso de redes para sepultar o defunto. Durante o velório o corpo do morto ficava em cima de uma esteira ou de uma porta no próprio chão batido para que todos pudessem velar o corpo e fazer as últimas orações ao morto. A rede era amarrada a um pedaço de madeira segurada por duas pessoas que se encarregavam de levar o defunto até o cemitério" (LIMA, 2013, p. 10). Outros sepultamentos demonstram a opulência de alguns enterros. Geralmente,

[...] [o] fundo do caixão ser forrado [...] de cor branca e tendo dentro um travesseiro. Durante o velório, o cadáver é iluminado por velas, muitas vezes trazidas por amigos e vizinhos, os familiares choram a perda do ente querido, juntamente com as carpideiras, se inicia a velada do corpo, durante toda a noite, e 
as rezas, orações pela alma do morto, e muitas palavras de saudade do defunto (OLIVEIRA, 2011, p.10).

Em relação ao enterro, "[...] [a] pompa fúnebre fazia parte da tradição cerimonial das confrarias, formando ao lado das festas de santo, importante fonte de seu prestígio. Todas as irmandades se comprometiam a acompanhar solenemente os membros à sepultura e em muitos casos, também a seus parentes" (OLIVEIRA, 2011, p.12). Associado ao grande o número de missas em sufrágio da alma do morto, que podia ser cantada, longa e solene com a presença de diversos padres ou na forma de um ritual simples.

\section{CONSIDERAÇÕES FINAIS}

De acordo com Rela (2011, p.4), o rito fúnebre e o sepultamento, juntamente com os paramentos do hábito mortuário,

marcam a transformação de um estado para outro. Como manifestação cultural, revelam valores e tradições de um grupo social. Ao final do século XIX, a atitude diante da morte e dos mortos foi tomando novas formas e novos sentidos. O tema se vincula a uma das preocupações maiores dos homens e mulheres daquele tempo: a preocupação com a boa morte. A morte não era vista como o fim do corpo, exclusivamente. A compreensão de uma vida eterna pelo espírito, fazia acreditar na morte como rito de passagem dessa vida para outra melhor. Falava-se ainda em inferno, purgatório e paraíso como uma geografia celeste após a morte.

Nesse contexto, o hábito mortuário devia ser determinado com muito cuidado e comprado antecipadamente, sendo guardado em lugar seguro, porém de conhecimento dos familiares, para ser usado na hora em que a morte chegasse. Havia a crença de que a roupa de defunto se "bem escolhida", podia conduzir o morto ao Reino do Céu, sem percalços, intercedendo em favor da sua alma, evitando que barreiras inesperadas interferissem nessa jornada. Ademais, a demonstração da humildade perante Deus, com a escolha de uma mortalha despojada de luxo, deixava aparente a sublimação da alma em relação à sua salvação e a absolvição dos pecados cometidos na vida material, se sobrepondo a todas as intercorrências negativas que por ventura tivesse cometido. Para Reis (1991, p.124), "servia de salvo-conduto na viagem rumo ao paraíso". A prevalência dessa 
percepção era possível, pois havia uma reminiscência do pensamento medieval português transmitido culturalmente para o Brasil Colonial, na indistinção entre corpo e alma. Assim, cuidar dos aspectos do corpo morto influenciava na direção que a alma poderia ter na geografia celestial. Por isso, muitas pessoas declaravam os tipos de mortalha que deveriam vestir nos testamentos (VAILATI, 2010 apud BRUNO, 2011, p. 118).

A preocupação com o bem morrer evitaria que a alma se perdesse no caminho do Reino de Deus e ficasse vagando pela terra. Essa lógica da salvação priorizava também a oração como mediadora entre o morto e o Divino Espírito Santo. Nesse ambiente,

[...] [a] prática da boa morte, significava cumprir com as determinações eclesiásticas para a obtenção da graça divina. Para tal, a Igreja Católica ao longo dos tempos não poupou esforços para a instituição de uma pedagogia do medo em torno da morte, do julgamento divino e da possibilidade de condenação transitória ou eterna como elementos de pressão sobre a consciência e o comportamento dos fiéis (RODRIGUES, 2005 apud BRUNO, 2011, p.114).

Assim, cabia ao cristão se preparar para a chegada da morte que podia avisá-lo com antecedência ou vir de surpresa sem que houvesse tempo para os cuidados necessários com as coisas da alma. Também em Sergipe, entre os anos de 1780 e 1850 , homens e mulheres se prepararam para a passagem do mundo dos vivos ao mundo dos mortos. Nessa economia da salvação determinaram os seus últimos desejos em relação aos bens materiais e às reservas de virtudes, referendadas na boa ação e nas práticas litúrgicas e sacramentais professadas pela Igreja Católica, por intermédio do que se estabelecia no Testamento, a ser cumprido por pessoa determinada, viabilizando assim, o alcance de um lugar eterno no Paraíso, ao lado de Deus.

\section{PRACTICE GOOD DIE AND USE OF SHROUD IN SERGIPE - NORTHEAST BRAZIL, 18TH AND 19TH CENTURIES}

\section{ABSTRACT}

Select clothing burial itself always raised expectations. The fear of death and of what was then made men and women cared to prepare, in advance, the clothing of the passage of material life to spiritual. In the collective imagination, Religious Christian predominated the idea that the use of the shroud facilitate the entry of the soul in God's 
Kingdom. The objective was to verify the choice of the shroud in Sergipe, from 17801850 , in 155 wills "to post mortem", the Judicial Archives of the State of Sergipe (AJES). Bibliographical and documentary research, based on the history of mentalities and content analysis method. The request of the shroud was made in this documentation, ranging from clothing preferred saints and invocations of Our Lady, to angel costumes, papal robes and white and black shrouds.

Keywords: Shroud. Mentality. Sergipe. Well die.

\section{REFERÊNCIAS}

ALENCASTRO, Luiz Felipe (Org.). História da vida privada no Brasil: império - a corte e a modernidade nacional. São Paulo: Companhia das Letras, 1998. v.2.

BRUNO, Aguiomar Rodrigues. O imaginário popular da morte numa província do Império. Revista Labirinto. Ano XI, no 15 dezembro de 2011. Disponível em: <file:///C:/Users/hortencia/Downloads/986-3464-2-PB.pdf>. Acesso em: 27 dez. 2015.

LIMA, Rafaela Moreira de. A conveniência da morte: os rituais fúnebres e o consumo mortuário em limoeiro do norte - ce. Anais... Simpósio Nacional de História, XXVII, 2013. ANPUH. Disponível em: <http://www.snh2013.anpuh.org/resources/anais/27/1364911292_ARQUIVO_ Artigo_ANPUH_Rafaela.pdf>. Acesso em: 22 jan.2015.

MATTOSO, Kátia M. de Queiróz. Bahia, século XIX: uma província no império. Rio de Janeiro: Nova Fronteira, 1992.

OLIVEIRA, Elene da Costa. A arte de bem morrer: a cultura funerária no Piauí do século XIX . Anais... Simpósio de e História Oitocentista, II. 2011. Disponível em: <http://www.outrostempos.uema.br/anais/pdf/oliveira2.pdf>. Acesso em: 25 jan. 2015.

REIS, João José. A morte é uma festa: ritos fúnebres e revolta popular no Brasil do século XIX. São Paulo: Companhia da Letras, 1992.

RELA, Eliana et al. A construção Social da Identidade de Grupo por Meio da Fotografia do Rito funerário. Anais... Simpósio Nacional de História, XXVI - ANPUH. São Paulo, julho 2011. Disponível em: <http://www.snh2011.anpuh.org/resources/anais/14/1300711783_ ARQUIVO_SUBMETIDO.ANPUH.pdf>. Acesso em: 23 jan.2015.

RIBEIRO, Ana Cláudia Anibal. Entre símbolos e palavras: o ato de velar em RussasCe. [s.n.t.]. Disponível em: <http://www.uece.br/eventos/encontrointernacionalmahis/ anais/trabalhos_completos/52-7199-03102012-144855.docx>. Acesso em: 20 jan. 2014.

SOUZA, Laura de Melo e (Org.). História da vida privada no Brasil: cotidiano e vida privada na América Portuguesa. São Paulo: Companhia das Letras, 1997. 